\section{Recruiting Students by Marketing Horticulture}

\author{
Margaret Balbath
}

Additional index words. curriculum, evaluations

Summary. The traditional content in introductory horticulture courses emphasizes plant structure, physiology, and production. At Illinois State Univ., however, the course work has been designed to meet University Studies requirements as well as departmental needs. The students taking the course are viewed as a market, and basic principles of marketing are used to gain and keep the interest of a wide variety of students, few of which have had any previous contact with horticulture. Extensive coverage is given to the historical, social, and economic status of horticulture in the United States. This nontraditional approach has been successful in the view of students and faculty. Postcourse surveys found that $98 \%$ of students felt that they had gained a good working knowledge of horticulture, and that $95 \%$ believed they would be a more knowledgeable consumer. Some departments use the University Studies program as a means of recruiting new majors, and this potential was not ignored in designing a marketing approach to the course content.

I ntroductory horticulture at Illinois State Univ. has been approved for inclusion in the University Studies Program. This program is comprised of courses whose content is considered of general importance to the educated layperson, rather than to the specialist in the field. Each University Studies course is expected to provide personal enrichment, be broad in scope, offer a systematic design for further learning, and assure a breadth of knowledge and understanding (Illinois State Univ., 1991). To meet these goals, the focus of introductory horticulture is on the

Department of Agriculture, Illinois State University. Normal, IL 61761 . economies of thevarious horticultural enterprises, how they have been affected by societal, economic, geographic, and climatic factors, and how the marketing of horticultural products and the impact of horticultural architectureaffects the personal lives of individuals.

Consumer goods are products purchased for personal use. The objective of restructuring introductory horticulture was to make it a "consumer good." The "market" was defined as students representing a variety of majors: history, psychology, theater, art, communications, finance, geography, biology, horticulture, and agriculture. Each of these majors was considered a market segment.

In the commercial world, marketers must be effective in serving selected market segments based on criteria such as demographic or psychographic characteristics, geographic location, or perceived benefits. When marketing introductory horticulture, perceived benefit is clearly the one criterion on which to base service to the (student) market segments.

Benefits to the market segments are created by relating horticulture to the particular major of the student, thereby integrating the general education in the exploration of a variety of common dimensions. For example, while there is general benefit for all students within each of the topics noted below, there are specific benefits for different majors. For the art major, the specific benefit is design-garden, landscape, and floral; for business, agribusiness, and economics majors, the benefit is the marketing of horticultural crops; for geography and history majors, the benefits are the history of the development of the western United States and of the national transportation systems resulting in majorchanges in thevegetable industry. For biology and horticulture majors, the benefits are the production of fruit trees, and the special work of breeding to satisfy consumer wants in turfgrasses, flowering shrubs, vegetables, and garden flowers.

The study of landscape design principles is conducive to a critical appreciation of a wide range of values beyond aesthetic ones, such as social, economic, and political. For example, home landscape design of the outdoor living area is extended readily to the site-planning of public outdoor spaces. Thesespaces make interesting study from several aspects: design, effect on behavior, useresponse by the public, and reflections on the social effects of the commercial privatization of formerly government-owned public spaces.

In conjunction with the topic of design of outdoor spaces, students are assigned three to four library readings, one in particular being Outdoor Spaces For Living And Learning (Marcus and Wischemann, 1987). Students then are presented with a mock proposal from the university provost containing his plans to redesign several areas of the campus. The students are to critique the provost's proposed plans. Because each stu- dent is familiar with the characteristics and use of the campus areas, the critique becomes one of real personal involvement, strengthened by a knowledge of site-planning gained from introductory horticulture.

Other topics that are presented and considered in relation to national issues include the economics of mechanical harvesting; pesticide usage; irrigation practices, and the legacy of the nation's water laws; congressional acts of the 19th century that helped the growth of the nursery industry; and the restructuring of the seed industry as a result of plant patents and advances in biotechnology.

Almost any topic in horticulture can be extended to give students learning experiences that explore connections among ideas from the perspectives of different disciplines. Thus, the University Studies objectives coincide with the departmental goal of broadening exposure to, and interest in, horticulture. The extensive use of 35mm color slides illustrating practically every aspect of every topic is an integral supporting component for achieving success in raising the students' level of interest, understanding, and appreciation.

At the start of the course, students completed a questionnaire in which they were asked to indicate those topics which 1) they are expected to learn something and 2) about which they would like to learn something. At the conclusion of the course, students completed a questionnaire querying their general satisfaction with the course and with the topics covered.

Comparing the pre- and postcourse questionnaires, the effectiveness of the course was analyzed for the degree to which the course 1) matched the students' expectations, 2) exceeded their expectations, 3) did not meet their expectations, 4) identified topics that were universally popular, and 5) identified topics that were not generally interesting to the students. Data reported here represents the responses of 59 students (29 in the Spring 1991 class and 30 in the Fall 1991 class). Average class size was 35 , of which $\approx 50 \%$ were freshmen.

The course has been taught for eight semesters, with generally positive acceptance indicated only through the departmental teacher evaluation procedure. The 1991 classes are the first to be surveyed through specific pre- and postcourse evaluation questionnaires that focused on course content and organization.

\section{Results and Discussion}

In comparing pre- and postcourse student attitudes, expectations, and interests for five selected topics (Table 1) from the postcourse survey showed that for all topics the positive response percentages were considerably higher than the expectations, strikingly so for floral design and fruit tree culture. Some of the added interest here 
Table 1. Pre- and postcourse attitude, expectation, and interest comparisons (selected topics).

\begin{tabular}{|c|c|c|c|}
\hline \multirow[b]{2}{*}{ Topic } & \multicolumn{2}{|c|}{ Precourse } & \multirow{2}{*}{$\begin{array}{l}\text { Postcourse } \\
\text { Found topic } \\
\text { of interesy" }\end{array}$} \\
\hline & $\begin{array}{l}\text { Expect to } \\
\text { cover }\end{array}$ & $\begin{array}{l}\text { Wish to } \\
\text { cover }^{2}\end{array}$ & \\
\hline Landscape design & 82 & 90 & 95 \\
\hline Home lawn care & 70 & 78 & 90 \\
\hline Floral design & 47 & 50 & 88 \\
\hline Fruit tree culture & 43 & 64 & 87 \\
\hline $\begin{array}{l}\text { Societal, geographic, } \\
\text { and economic forces }\end{array}$ & --- & 49 & 69 \\
\hline
\end{tabular}

Percentage of respondents expressing an opinion.

"Percentage of respondents who found topic of interest.

${ }^{x}$ Topic not included as expected coverage.

may be attributed to the instructors experience in teaching floral design and to the use of slides of field workers performing grafting and budding. The very high interest in landscape design was not surprising, but the fairly low initial interest in lawn care was notable considering the generally massive commercial attention targeted to lawns and lawn care products. The history of horticulture as affected by societal, geographic, and economic forces made considerable gain in student interest, but could not match the more aesthetic design topics or even the pragmatic lawn care and fruit tree culture.

Table 2, Part A shows the postcourse ratings of topics that were new to the majority of students. It was not surprising that the design topics received the highest ratings, the basis for which lies in the very high precourse interest in landscape design shown initially by $90 \%$ of the students (Table 1).

The other three topics in Part A proved to be interesting to more than half of the students, yet much less so than the design topics. This response is reasonable given that not only were these topics new and unfamiliar to the majority of students, but also their study requires an integration of widely disparate and unfamiliar concepts, a process with which most are not familiar.

The influence of presumed lack of background knowledge and subject matter familiarity is again apparent in the low interest results shown for the topics in Part B of Table 2, This was disappointing but not unexpected. The fact that even half the students found these topics of interest may be viewed as a gain, since such ideas rarely are introduced in classes at this level.

Table 3 shows the positive response percentages toward the content of the course as a whole. The survey's questions, here relating primarily to University Studies goals, indicate that the topics covered were considered to be of high personal value to the students. The very high positive response of $98 \%$ satisfaction indicating that students felt they had a working knowledge of horticulture is probably the best measure of the success in marketing horticulture.

Table 2. Postcourse ratings of topics that were new to most students.

Topic Percent positive $^{2}$

Part A (topics receiving positive ratings)

Design of outdoor public spaces

Design and drafting of a flower garden

Design and drafting of a group planting

Societal, geographic, and economic forces affecting horticulture

Water laws and development of the western United States

Marketing of horticultural crops (as compared to other horticultural crops)

Part B (topics of divided interest)

Mechanical harvesting

Economics of world trade

Plant patents

Marketing orders impact on consumers

History of development of vegetable production areas

${ }^{2}$ Percentage of respondents who stated coverage of the topic had been of interest.

${ }^{y}$ A project assignment for each student.

Table 3. Student perception of accomplishment of overall course goats (postcourse response).

\begin{tabular}{|lc|}
\hline Goal & $\begin{array}{c}\text { Percent } \\
\text { response }^{2}\end{array}$ \\
\hline Working knowledge of horticulture & 98 \\
Knowledge gained will help student to be a more informed consumer & 95 \\
Choice of topics appropriate for the level of the course & 90 \\
Knowledge gained was worth the investment of time and cost & 87 \\
Meets expectations of a university studies course & 84 \\
\hline 2Percentaoe of respondents expressina a choice & \\
\end{tabular}

